\title{
Prevalence and factors associated with HCV infection among elderly individuals in a southern Brazilian city
}

\author{
Tatiana Martins ${ }^{[1]}$, Danúbia Felippe Grassi de Paula Machado ${ }^{[1]}$, \\ Fabiana Schuelter-Treviso[ ${ }^{[1]}$, Daisson José Treviso[ ${ }^{[1]}$, Roger Augusto Vieira e Silva ${ }^{[2]}$, \\ Janaína Luz Narciso-Schiavon ${ }^{[1],[3]}$ and Leonardo de Lucca Schiavon ${ }^{[1],[3]}$
}

[1]. Programa de Pós-Graduação em Ciências da Saúde, Universidade do Sul de Santa Catarina, Tubarão, SC. [2]. Prefeitura Municipal de Tubarão, Tubarão, SC. [3]. Divisão de Gastroenterologia, Universidade Federal de Santa Catarina, Florianópolis, SC.

\begin{abstract}
Introduction: Few Latin American studies have assessed the prevalence of hepatitis C virus (HCV) infection in elderly individuals, in whom the highest rates are expected. We aimed to investigate the prevalence of and factors associated with HCV infection in elderly residents in the municipality of Tubarão, Santa Catarina. Methods: This cross-sectional study included 820 individuals (aged $\geq 60$ years) who were selected by simple random sampling. The presence of anti-HCV antibodies was tested by chemiluminescence, and HCV RNA detection was performed for the anti-HCV-reactive subjects. Those individuals who were anti-HCV reactive but had undetectable HCV RNA levels were tested using a third-generation recombinant immunoblot assay. The variables were compared using the chi-squared test or Fisher's exact test, and those variables with $\mathrm{p}<0.05$ were included in the logistic regression model. Results: The mean patient age was 68.6 years (SD 7.0 years); $39 \%$ were men, and $92 \%$ were Caucasian. Eighteen subjects were anti-HCV positive. Among these individuals, 4 were characterized as false-positives, leaving $14(1.7 \%)$ individuals with confirmed infections for analysis. HCV infection was associated with an age older than 65 years, households with 3 or more residents and the previous transfusion of blood products. In the logistic regression analysis, the following variables were independently associated with $\mathrm{HCV}$ infection: households with 3 or more residents (OR 7.9, 95\% CI $1.7-35.9, p=0.008)$ and previous blood transfusion (OR 6.2,95\% CI 2.1-18.6, $p=0.001)$. Conclusions: The HCV prevalence in the elderly population in the municipality of Tubarão was higher than that found in previous studies of blood donors in the same region. Although exposure to contaminated blood products remained important, other transmission routes, such as household transmission, could play a role in $\mathrm{HCV}$ infection.
\end{abstract}

Keywords: Hepatitis C. Epidemiology. Transmission. Prevalence. Risk factors.

\section{INTRODUCTION}

Chronic hepatitis $\mathrm{C}$ virus (HCV) infection is a major cause of liver disease worldwide. Although the prevalence varies geographically, it is estimated that $2.3 \%$ of the world's population are $\mathrm{HCV}$ carriers, a percentage that represents over 160 million infected people worldwide ${ }^{1}$. The primary risk factors for HCV infection include the transfusion of blood products from unscreened donors, intravenous drug use, organ transplantation and hemodialysis ${ }^{2,3}$. Significant proportions of chronically infected individuals are asymptomatic and remain undiagnosed for many years, representing a natural reservoir for the further transmission of $\mathrm{HCV}^{4}$. Approximately $20 \%$ of chronic HCV carriers will progress to cirrhosis, and the 5-year

Address to: Dr. Leonardo de Lucca Schiavon. Rua Durval Pires da Cunha 210, 88051-150 Florianópolis, SC, Brasil.

Phone/Fax: 5548 3209-6854

e-mail: leo-jf@uol.com.br

Received 5 February 2013

Accepted 4 June 2013 risk of progressing to decompensation is approximately $18 \%$ in those subjects with established cirrhosis ${ }^{5,6}$. In addition, there is an increased risk of developing hepatocellular carcinoma in individuals with cirrhosis caused by $\mathrm{HCV}$, with an estimated annual incidence of $1-5 \%$ per year? ${ }^{7}$. Overall, it is estimated that over 350,000 deaths occur annually as a result of $\mathrm{HCV}$ infection ${ }^{8}$.

Studies in various parts of the world have found a higher prevalence of hepatitis $\mathrm{C}$ in elderly populations ${ }^{9-13}$. This epidemiological profile is most likely related to increased exposure to specific risk factors, such as the transfusion of blood products before HCV screening was introduced in blood banks and having undergone medical or therapeutic procedures performed under poor conditions and without the current standard precautionary measures. In addition, older age is associated with disease progression and is related to more advanced stages of fibrosis, higher rates of fibrosis progression and an increased incidence of hepatocellular carcinoma ${ }^{14}$. Because of these relationships, it is likely that the prevalence of and factors associated with HCV infection among elderly individuals will provide important tools for developing health policy strategies. 
A population-based study conducted by the Ministry of Health found a prevalence of $1.38 \%$ for anti-HCV antibodies, with significantly higher rates among those older than 60 years ${ }^{15}$. However, that study included only individuals aged up to 69 years and was performed in state capitals; therefore, it did not reflect the situation in less urbanized regions and inner cities. The purpose of this study was to estimate the prevalence of and investigate possible factors associated with hepatitis $\mathrm{C}$ infection among elderly individuals in the municipality of Tubarão, southern Brazil.

\section{METHODS}

\section{Study population}

An observational cross-sectional population-based study was conducted between June 2010 and March 2011 in the municipality of Tubarão, located in the State of Santa Catarina, southern Brazil. Individuals aged 60 years (completed in 2010) and older who were enrolled in the Family Health Strategy (FHS) Program were included in the study. Individuals who refused or declined to participate and those who did not attend the blood collection appointment were excluded. The FHS program is a strategic initiative of the Brazilian Public Health System; it involves multidisciplinary teams and aims to promote health, disease prevention and recovery and rehabilitation after illness. The FHS Program of Tubarão has a good coverage rate, totaling 9,009 elderly subjects in June 2010 (75.4\% of elderly residents in the municipality according to the last Brazilian census).

Assuming an estimated prevalence rate of $1.5 \%$ for $\mathrm{HCV}$ in the population ${ }^{16}$ and using a $95 \%$ confidence interval (CI) and an accuracy of $0.8 \%$, the estimated sample size was 808 individuals ${ }^{17}$. Anticipating possible losses, 207 additional subjects $(25 \%)$ were included, totaling 1,015 subjects who were selected by simple random sampling. A pre-survey of all elderly subjects enrolled in the health units was conducted, and the data were entered into a spreadsheet to perform random sampling using the Random Generator for Microsoft ${ }^{\circledR}$ Excel ${ }^{\circledR}$ (Add-in Express Ltd, Homel, Belarus).

\section{Data collection}

Participants were interviewed at home after being informed that all data collected would be kept strictly confidential. The structured questionnaire consisted of closed questions on sociodemographic characteristics, medical and surgical history and risk behaviors, including drug use and sexual behavior. Blood transfusions prior to 1993 are considered to be greater risk factors for $\mathrm{HCV}$ transmission because $\mathrm{HCV}$ screening tests were introduced in the majority of Brazilian blood banks in 1992. Alcoholism was defined as $\geq 2$ affirmative responses to the CAGE questionnaire ${ }^{18}$. Individuals who reported having smoked $\geq 100$ cigarettes in their lifetimes were considered smokers (current or previous) ${ }^{19}$.

In the present study, invasive procedures were defined as all surgical procedures during which the skin or mucous membranes were incised or an instrument was introduced through a natural body orifice. This definition includes all surgical procedures, minimally invasive dermatological interventions, techniques such as percutaneous transluminal angioplasty and cardiac catheterization, minimally invasive procedures involving biopsies or the placement of probes or catheters requiring entry into a body cavity through a needle or trocar and endoscopic procedures.

After the interview, the participants were scheduled for blood collection at an FHS unit. Home collections were performed for the individuals with limited mobility. The samples were centrifuged in situ by the collection team and transported to the Clinical Laboratory of Unisul for testing. In the case of household blood collection, the samples were immediately transported to the laboratory and then centrifuged and processed.

\section{Laboratory analyses}

The presence of anti-HCV antibodies was assessed using enhanced chemiluminescence (Vitros. Eci, Johnson \& Johnson, USA). A qualitative analysis of the HCV RNA level was performed for those individuals who were anti-HCV reactive. The polymerase chain reaction (PCR) method was used and was performed with the AMPLICOR ${ }^{\circledR}$ HCV Test 2.0 kit (Roche Molecular Systems, Branchburg, NJ, USA), which has a lower detection limit of $50 \mathrm{IU} / \mathrm{mL}$. Individuals who were anti-HCV reactive but had an undetectable HCV RNA level were tested using a third-generation recombinant immunoblot assay (HCV RIBA) to differentiate between previous contact with $\mathrm{HCV}$ and false-positivity for anti-HCV antibodies. Subjects who were anti-HCV reactive and positive according to the HCV RNA PCR or the HCV RIBA were considered to have a confirmed $\mathrm{HCV}$ infection (current or previous).

\section{Statistical analysis}

Numerical variables were expressed as the mean and standard deviation (SD), and categorical variables were expressed as absolute numbers and proportions. Pearson's chi-squared and Fisher's exact tests were used to compare proportions, and $\mathrm{p}<0.05$ was considered statistically significant.

To identify the parameters independently associated with $\mathrm{HCV}$ infection, the variables with $\mathrm{p}<0.050$ in the univariate analysis were evaluated by logistic regression using the Enter method. The discrimination capability of the final model was evaluated using the area under the receiver operating characteristic curve (AUROC), and the goodness-of-fit of the logistic model was verified by the Hosmer-Lemeshow test ( $p>0.05$ indicated a model with appropriate adjustment). All statistical tests were performed using SPSS, version 17.0 (SPSS, Chicago, IL, USA).

\section{Ethical considerations}

The study protocol conformed to the ethical guidelines of the 1975 Helsinki Declaration and the Brazilian regulations concerning research involving human subjects. This study was approved by our institutional review board. 


\section{RESULTS}

\section{Sample characteristics}

Among the 1,015 subjects randomly selected for inclusion in the study, 122 did not attend the interview for the following reasons: 8 died, five moved to other cities, 11 were not found and 98 refused to participate. Of the 893 individuals who were interviewed, 73 did not attend the appointment for blood collection and were excluded from the final analysis.

The characteristics of the included subjects and the comparison of these subjects with the excluded individuals (73 interviewed) are shown in Table 1. Compared with the excluded subjects, the subjects included in the analysis had a higher proportion of stable relationships (married or cohabiting) and were less likely to share personal items with non-household members. No differences were observed with respect to the other variables.

Among the included subjects, the mean age was 68.6 years (SD 7.0 years), $38.5 \%$ were men, and $92.4 \%$ were Caucasian. The mean duration of schooling was 4.2 years (SD 3.4 years), and $51.5 \%$ of the subjects had 4 or more years of schooling. With regard to marital status, $66 \%$ were living in stable relationships (married or cohabiting couples), and $43 \%$ were living with 3 or more people in the household.

Concerning the variables related to exposure and risk factors, alcohol abuse was observed in $10.1 \%$ of the subjects, current or previous smoking was observed in $40.6 \%$, and illicit drug use was observed in only $0.4 \%$. None of the subjects reported intravenous drug use. Only $2.5 \%$ of the surveyed participants reported having 2 or more sexual partners during the past year, and $97.8 \%$ reported that they did not use condoms regularly. A history of blood transfusion was observed for $15.8 \%$ of the subjects, $49.6 \%$ of whom had undergone transfusions before 1993 (7.8\% of all included subjects). Invasive procedures were reported by $60.8 \%$ of participants, $8 \%$ had undergone acupuncture treatments, and $0.2 \%$ had been tattooed. The survey indicated that $30.5 \%$ of the subjects routinely shared personal items, $16.9 \%$ of whom shared these items with family members; $15.1 \%$ shared them with unrelated people. In addition, $9.1 \%$ of the respondents had already undergone human immunodeficiency virus (HIV) screening, and 2 individuals were HIV positive.

\section{Prevalence of markers for $\mathrm{HCV}$ infection}

As shown in Figure 1, anti-hepatitis $\mathrm{C}$ virus reactivity detected by chemiluminescence was observed for 18 subjects

TABLE 1 - Characteristics of the included subjects and a comparison with the excluded individuals.

\begin{tabular}{|c|c|c|c|c|c|}
\hline \multirow[b]{2}{*}{ Variable } & \multicolumn{2}{|c|}{$\begin{array}{l}\text { Included } \\
(\mathrm{n}=820)\end{array}$} & \multicolumn{2}{|c|}{$\begin{array}{c}\text { Excluded } \\
(\mathrm{n}=73)\end{array}$} & \multirow[b]{2}{*}{$\mathrm{p}^{*}$} \\
\hline & $\mathrm{n}$ & $\%$ & $\mathrm{n}$ & $\%$ & \\
\hline Age $\geq 65$ years & 530 & 64.6 & 47 & 64.4 & $0.966^{\mathrm{q}}$ \\
\hline Male & 316 & 38.5 & 23 & 31.5 & $0.244^{\mathrm{q}}$ \\
\hline Caucasian* & 756 & 92.4 & 65 & 89.0 & $0.343^{\mathrm{q}}$ \\
\hline Schooling $<4$ years & 422 & 51.5 & 30 & 41.7 & $0.255^{\mathrm{q}}$ \\
\hline Stable relationship & 541 & 66.0 & 36 & 49.3 & $0.007^{\mathrm{q}}$ \\
\hline Household with 3 or more residents & 353 & 43.0 & 32 & 43.8 & $0.881^{\mathrm{q}}$ \\
\hline Alcoholism & 83 & 10.1 & 7 & 9.6 & $0.911^{\mathrm{q}}$ \\
\hline Current/previous smoking & 331 & 40.6 & 34 & 47.2 & $0.271^{\mathrm{q}}$ \\
\hline History of drug use & 3 & 0.4 & 0 & 0.0 & $1.000^{\mathrm{f}}$ \\
\hline No regular use of condoms & 795 & 97.8 & 64 & 95.5 & $0.210^{\mathrm{f}}$ \\
\hline Two or more sexual partners $\#$ & 20 & 2.5 & 3 & 4.3 & $0.416^{\mathrm{f}}$ \\
\hline Transfusion of blood products & 129 & 15.8 & 7 & 9.7 & $0.173^{\mathrm{q}}$ \\
\hline Transfusion before 1993 & 64 & 7.8 & 3 & 4.2 & $0.262^{\mathrm{f}}$ \\
\hline History of invasive procedures & 497 & 60.8 & 42 & 58.3 & $0.671^{\mathrm{q}}$ \\
\hline Acupuncture & 68 & 8.3 & 8 & 11.1 & $0.413^{\mathrm{q}}$ \\
\hline Tattoo & 2 & 0.2 & 1 & 1.4 & $0.225^{f}$ \\
\hline Sharing personal hygiene objects & 249 & 30.5 & 24 & 33.8 & $0.550^{\mathrm{q}}$ \\
\hline Sharing with household members & 138 & 16.9 & 8 & 11.3 & $0.226^{\mathrm{q}}$ \\
\hline Sharing with non-household members & 123 & 15.1 & 18 & 25.4 & $0.023^{\mathrm{q}}$ \\
\hline Previous HIV testing & 74 & 9.1 & 5 & 7.0 & $0.560^{\mathrm{q}}$ \\
\hline
\end{tabular}

${ }^{\mathrm{q}}$ Chi-squared test; ${ }^{*}$ Self-reported; fFisher's exact test; ${ }^{*}$ Within the past 12 months; HIV: human immunodeficiency virus. 
$(2.2 \%, 95 \%$ CI $1.2 \%-3.2 \%)$. Among these subjects, 14 had an HCV RNA detectable by PCR $(1.7 \%, 95 \%$ CI $1.0 \%-2.9 \%)$; and HCV RNA was undetectable in the remaining subjects $(0.5 \%)$. For the 4 subjects with undetectable HCV RNA levels, the HCV RIBA was performed. RIBA was negative for 2 subjects and indeterminate for the remaining 2 . The individuals with indeterminate RIBA results had anti-HCV by chemiluminescence near the lower limit of detection (cut-off points 1.79 and 2.16); thus, these individuals were considered negative in the analysis of risk factors. The prevalence of confirmed $\mathrm{HCV}$ infection was $0.6 \%$ among the subjects aged $60-65$ years and $2.5 \%$ among those over 65 years.

\section{Analysis of factors associated with $\mathrm{HCV}$ infection}

As detailed in Table 2, compared with elderly subjects without $\mathrm{HCV}$ infection, the infected subjects included a higher percentage of individuals over age 65 years $(85.7 \%$ vs. $58.3 \%$, $\mathrm{p}=0.039$ ), a higher proportion of households with 3 or more residents $(85.7 \%$ vs. $42.3 \%, p=0.001)$ and a higher proportion of subjects who had undergone transfusions of blood products $(57.1 \%$ vs. $15 \%, \mathrm{p}<0.001)$. When the subjects were evaluated only regarding blood transfusion prior to 1993 , there was a trend toward a higher frequency of exposure to blood products among

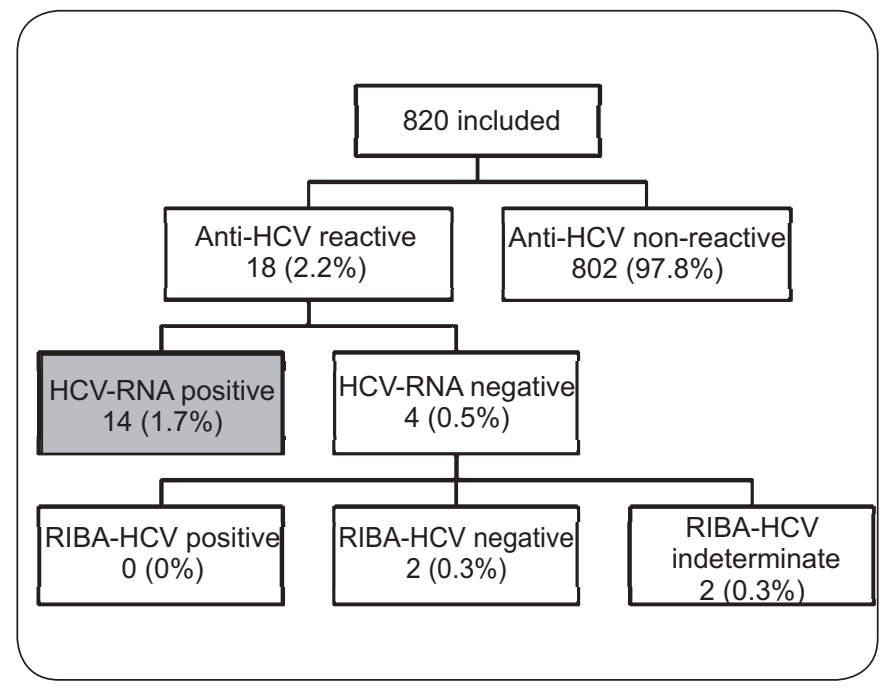

FIGURE 1 - Flowchart detailing the included subjects according to HCV infection markers. RIBA: recombinant immunoblot assay; $\mathrm{HCV}$ : hepatitis $\mathrm{C}$ virus; RNA: ribonucleic acid.

those with $\mathrm{HCV}$ infection than their uninfected counterparts $(23.1 \%$ vs. $7.7 \%, p=0.076)$. No differences were observed with respect to the other variables.

TABLE 2 - Univariate analysis of factors associated with HCV infection.

\begin{tabular}{|c|c|c|c|c|c|}
\hline \multirow[b]{2}{*}{ Variable } & \multicolumn{2}{|c|}{$\begin{array}{c}\mathrm{HCV}- \\
(\mathrm{n}=806)\end{array}$} & \multicolumn{2}{|c|}{$\begin{array}{l}\mathrm{HCV}+ \\
(\mathrm{n}=14)\end{array}$} & \multirow[b]{2}{*}{$\mathrm{p}$} \\
\hline & $\mathrm{n}$ & $\%$ & $\mathrm{n}$ & $\%$ & \\
\hline Age $>65$ years & 470 & 58.3 & 12 & 85.7 & $0.039^{\mathrm{q}}$ \\
\hline Male & 309 & 38.3 & 7 & 50.0 & $0.374^{\mathrm{q}}$ \\
\hline Caucasian* & 744 & 92.5 & 12 & 85.7 & $0.287^{f}$ \\
\hline Schooling $<4$ years & 394 & 48.9 & 4 & 28.6 & $0.132^{\mathrm{q}}$ \\
\hline Stable relationship & 530 & 65.8 & 11 & 78.6 & $0.403^{\mathrm{f}}$ \\
\hline Household with 3 or more residents & 341 & 42.3 & 12 & 85.7 & $0.001^{\mathrm{q}}$ \\
\hline Alcoholism & 81 & 10.1 & 2 & 14.3 & $0.645^{\mathrm{f}}$ \\
\hline Current/previous smoking & 324 & 40.4 & 7 & 50.0 & $0.468^{\mathrm{q}}$ \\
\hline History of drug use & 3 & 0.4 & 0 & 0.0 & $1.000^{\mathrm{f}}$ \\
\hline No regular use of condoms & 782 & 97.9 & 13 & 92.9 & $0.271^{\mathrm{f}}$ \\
\hline Two or more sexual partners ${ }^{\#}$ & 19 & 2.4 & 1 & 7.1 & $0.296^{\mathrm{f}}$ \\
\hline Transfusion of blood products & 121 & 15.0 & 8 & 57.1 & $0.001^{\mathrm{f}}$ \\
\hline Transfusion before 1993 & 61 & 7.7 & 3 & 21.1 & $0.076^{\mathrm{f}}$ \\
\hline History of invasive procedures & 488 & 60.7 & 9 & 64.3 & $0.785^{\mathrm{q}}$ \\
\hline Acupuncture & 68 & 8.4 & 0 & 0.0 & $0.621^{\mathrm{f}}$ \\
\hline Tattoo & 2 & 0.2 & 0 & 0.0 & $1.000^{\mathrm{f}}$ \\
\hline Sharing personal hygiene objects & 245 & 30.5 & 4 & 28.6 & $1.000^{\mathrm{f}}$ \\
\hline sharing with household members & 136 & 17.0 & 2 & 14.3 & $1.000^{\mathrm{f}}$ \\
\hline sharing with non-household members & 120 & 15.0 & 3 & 21.4 & $0.455^{\mathrm{f}}$ \\
\hline Previous HIV testing & 72 & 9.0 & 2 & 14.3 & $0.369^{\mathrm{f}}$ \\
\hline
\end{tabular}

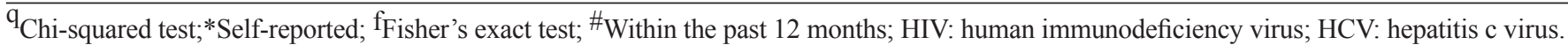


TABLE 3 - Logistic regression analysis of the factors associated with hepatitis c virus infection (variables with $p<0.050$ in the univariate analysis were included).

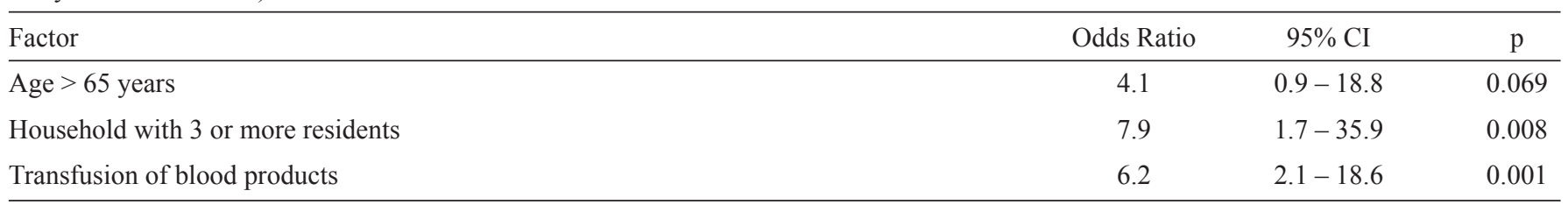

CI: confidence interval.

A multiple logistic regression analysis was performed using the presence of HCV infection as the dependent variable. The following variables with $\mathrm{p}<0.050$ were included in the regression model: age $>65$ years, households with 3 or more residents and the transfusion of blood products. The variable transfusion before 1993 was not included because the blood transfusion variable was already included in the model. In the multivariate analysis (Table 3), the variables that were independently associated with $\mathrm{HCV}$ infection were households with 3 or more residents (OR 7.9, $95 \%$ CI $1.7-35.9, \mathrm{p}=0.008$ ) and a history of blood transfusion (OR 6.2, 95\% CI $2.1-18.6, p=0.001$ ). The Hosmer-Lemeshow goodness-of-fit test yielded a $p$ value of 0.179 ; thus, the final model was considered adequate. The AUROC of the final model was 0.827 (95\% CI $0.690-0.965, \mathrm{p}<0.001)$, which was indicative of good discrimination capability.

\section{DISCUSSION}

To our knowledge, this is the first population-based study in a Brazilian city with the aim of determining the prevalence of $\mathrm{HCV}$ infection among elderly individuals. Most previous Brazilian studies on the prevalence of hepatitis $\mathrm{C}$ have significant limitations and have been generally conducted with small groups that were usually not representative of the general population (e.g., blood donors). In addition, the inappropriate sample sizes and the inadequate methodology that were often used may have restricted the validity and generalizability of the results of these studies.

The seroprevalence of hepatitis $\mathrm{C}$ (anti-HCV reactive in the chemiluminescence assay) in this study was $2.2 \%$ (95\% CI $1.2 \%-3.2 \%$ ), and the prevalence of confirmed current $\mathrm{HCV}$ infection was $1.7 \%$ (95\% CI 1.0\%-2.9\%). These prevalences are significantly higher than those observed in the studies of blood donors, which found a seroprevalence of $1.2 \%$ in Brazil, $0.3 \%$ in the State of Santa Catarina and $0.3 \%$ in the City of Tubarão ${ }^{20,21}$. A population-based study conducted in São Paulo, Brazil, found that the prevalence of anti-HCV antibodies was $1.4 \%$ in the general population and $3.2 \%$ among individuals older than 60 years, suggesting that the prevalence is higher than that observed in studies of blood donors and is even higher among elderly individuals ${ }^{22}$. However, only 90 individuals older than 60 years were tested in that study, which may have adversely impacted the reliability and validity of the outcomes. The divergence between the prevalence detected among blood donors and that observed in the present study suggests that there is a higher prevalence of hepatitis $\mathrm{C}$ among elderly individuals. However, this difference may reflect other specific characteristics of blood donors in whom lower HCV infection rates are often observed.

In 2011, the data from the largest study ever conducted in Brazil on the prevalence of viral hepatitis were released ${ }^{15}$. The study included 19,634 individuals aged between 10 and 69 years who were residents of Brazilian state capitals. The overall prevalence of anti-HCV positivity was $1.4 \%$, ranging from $0.7 \%$ in the Northeast Region to $2.1 \%$ in the North Region. In the South Region, the prevalence was $1.2 \%$, which is lower than that observed in the elderly population in the municipality of Tubarão. When considering only subjects aged between 60 and 69 years, the study conducted by the Ministry of Health found a global seroprevalence of $3.3 \%$. However, no data regarding the different age groups were reported specifically for the South Region ${ }^{15}$. Despite its undeniable importance, that study had several major limitations, such as the inclusion of individuals aged only up to 69 years and the relatively small number of elderly individuals who were included (862 individuals). In addition, because the study included only populations from large cities, the results most likely do not accurately reflect the epidemiological characteristics of small- and medium-sized cities.

In the univariate analysis, the variables age older than 65 years, households with 3 or more residents and the transfusion of blood products were associated with HCV infection. The last 2 variables remained independently associated with $\mathrm{HCV}$ infection in the logistic regression analysis.

Although the direct relationship between age and the prevalence of hepatitis has already been described, few studies have specifically investigated older age as a factor associated with $\mathrm{HCV}$ infection ${ }^{23}$. However, as previously mentioned, the 2 main Brazilian population-based studies have identified a higher prevalence of $\mathrm{HCV}$ among older individuals ${ }^{15-24}$. It is possible that elderly subjects have lived most of their lives exposed to potential risk factors, such as the transfusion of contaminated blood products and medical and therapeutic procedures performed without standard precautionary measures. Although age was not associated with $\mathrm{HCV}$ infection in the multivariate analysis, in this study, the prevalence in individuals older than 65 years was 4 times greater than that in the other age groups $(2.5 \%$ vs. $0.6 \%)$. These findings are most likely related to a shift in the incidence curve toward older age after appropriate measures to control $\mathrm{HCV}$ transmission were implemented in Brazil, particularly the implementation of anti-HCV screening in blood banks in the early $1990 \mathrm{~s}^{23}$. 
In the present study, an association between $\mathrm{HCV}$ infection and living in a household with 3 or more residents was observed. There have been few studies on the relationship between $\mathrm{HCV}$ infection and the number of people in the household. Presumably, this finding may be linked to the household transmission of $\mathrm{HCV}$, either related or unrelated to sexual activities $^{25}$. Another plausible explanation is that the number of people in the household is a confounding variable that may be connected to other socioeconomic or exposure variables that were not investigated in this study.

Previous blood transfusions were independently associated with $\mathrm{HCV}$ infection in this study. The variable transfusion before 1993 was not included in the regression analysis because the blood transfusion variable was already included in the model. The broader variable (previous blood transfusions) was used in an attempt to overcome a possible recall bias related to the more restricted variable (transfusion before 1993). An important study that investigated the period between 1960 and 1991 demonstrated the relevance of blood transfusion as a risk factor for $\mathrm{HCV}$ infection ${ }^{26}$. In that study, between $5 \%$ and $15 \%$ of blood-product recipients were infected with $\mathrm{HCV}^{26}$.

After the adoption of anti-HCV screening tests, the risk of $\mathrm{HCV}$ infection through blood transfusion was significantly reduced and it is currently about one in 1,657,722 units of blood transfused in the United States of America ${ }^{27}$. A Brazilian study showed that the probability of contamination by $\mathrm{HCV}$ was still 1 in 13,721 units of blood transfused ${ }^{28}$, a significantly higher rate than that observed in developed countries ${ }^{28}$. In Brazil, the routine use of molecular biology-based tests to screen blood units has been implemented over the past years. This procedure will most likely reduce the rate of post-transfusion $\mathrm{HCV}$ infection. It is likely that the findings of the present study reflect greater exposure to contaminated blood products before the beginning of systematic HCV screening. This hypothesis is corroborated by the trend toward a higher frequency of exposure to blood products before 1993 observed among those with $\mathrm{HCV}$ infection than among their uninfected counterparts.

There was no association between a history of invasive procedures and HCV infection. Despite the lack of reliable data, it is estimated that approximately 2 million individuals worldwide are infected by HCV each year because of invasive procedures $^{29}$. It is possible that these findings are related to the high proportion of individuals that were previously subjected to procedures that were considered invasive. Thus, it is likely that a more detailed variable that includes the type of procedure (e.g., in-patient or out-patient), the magnitude or extent (small, medium and large) and the individual who performed the procedure (i.e., health professional or layperson) would provide better information on this risk factor.

Other important exposure variables, such as illicit drug use, acupuncture and tattooing, were also not associated with HCV infection. With regard to drug use and a history of tattooing, the low frequencies observed in this study explain the outcomes. However, intravenous drugs and inhaled cocaine have been found to be associated with HCV infection and remain important risk factors ${ }^{15,30}$. Acupuncture remains controversial as a risk factor for $\mathrm{HCV}$ infection. Although some studies have observed an association between HCV infection and acupuncture treatment, this association was weak and predominantly found in Asian studies ${ }^{31}$.

Some limitations of this study should be discussed. First, the differences between the included and excluded individuals regarding marital status and the proportion of subjects who share personal items with non-household members may suggest selection bias. However, such bias is unlikely because the proportion of excluded subjects was relatively small, and these excluded individuals were similar to the included individuals with respect to all other major characteristics. Finally, the study design used does not allow the establishment of direct causal relationships or the temporal sequence between the variables investigated and HCV infection. This issue is a common limitation of cross-sectional studies and can be resolved with cohort studies $^{32}$. Nevertheless, cross-sectional populationbased studies represent useful tools for public health planning, understanding disease etiology and hypothesis generation ${ }^{33}$.

In conclusion, the prevalences of positive serology for hepatitis $\mathrm{C}$ and confirmed HCV infection in the elderly population of the municipality of Tubarão were $2.2 \%$ and $1.7 \%$, respectively, which are substantially higher than the results observed in studies of blood donors performed in the same municipality. HCV infection was associated with older age (univariate analysis), a higher number of people in the household and the transfusion of blood products (in univariate and multivariate analyses). The association between a greater number of household members and HCV infection may be related to household $\mathrm{HCV}$ transmission or other socioeconomic and exposure variables that were not investigated in this study. The association between older age and blood-product transfusion confirms the importance of transfusion risk, particularly among elderly individuals, and reinforces the hypothesis that the prevalence of $\mathrm{HCV}$ is higher in older age groups.

\section{CONFLICT OF INTEREST}

The authors declare that there is no conflict of interest.

\section{FINANCIAL SUPPORT}

This study was supported by Conselho Nacional de Desenvolvimento Científico e Tecnológico (CNPq), Fundação de Amparo à Pesquisa e Inovação do Estado de Santa Catarina (FAPESC) and Tubarão City Hall.

\section{REFERENCES}

1. Lavanchy D. Evolving epidemiology of hepatitis $\mathrm{C}$ virus. Clin Microbiol Infect 2011; 17:107-115.

2. Alter MJ. Epidemiology of hepatitis $\mathrm{C}$ virus infection. World $\mathrm{J}$ Gastroenterol 2007; 13:2436-2441.

3. Shepard CW, Finelli L, Alter MJ. Global epidemiology of hepatitis C virus infection. Lancet Infect Dis 2005; 5:558-567. 
4. Massard J, Ratziu V, Thabut D, Moussalli J, Lebray P, Benhamou Y, et al. Natural history and predictors of disease severity in chronic hepatitis C. J Hepatol 2006; 44:S19-S24.

5. Fattovich G, Giustina G, Degos F, Tremolada F, Diodati G, Almasio $\mathrm{P}$, et al. Morbidity and mortality in compensated cirrhosis type C: a retrospective follow-up study of 384 patients. Gastroenterology 1997; $112: 463-472$

6. Alberti A, Vario A, Ferrari A, Pistis R. Review article: chronic hepatitis C--natural history and cofactors. Aliment Pharmacol Ther 2005; 22 (suppl II):74-78.

7. Afdhal NH. The natural history of hepatitis C. Semin Liver Dis 2004; 24 (Supl II):3-8.

8. Hatzakis A, Wait S, Bruix J, Buti M, Carballo M, Cavaleri M, et al. The state of hepatitis B and C in Europe: report from the hepatitis B and C summit conference*. J Viral Hepat 2011; 18 (supl I):1-16.

9. Dominguez A, Bruguera M, Vidal J, Plans P, Salleras L. Communitybased seroepidemiological survey of HCV infection in Catalonia, Spain. J Med Virol 2001; 65:688-693.

10. Chen CH, Yang PM, Huang GT, Lee HS, Sung JL, Sheu JC. Estimation of seroprevalence of hepatitis B virus and hepatitis $\mathrm{C}$ virus in Taiwan from a large-scale survey of free hepatitis screening participants. J Formos Med Assoc 2007; 106:148-155.

11. Cozzolongo R, Osella AR, Elba S, Petruzzi J, Buongiorno G, Giannuzzi $\mathrm{V}$, et al. Epidemiology of $\mathrm{HCV}$ infection in the general population: a survey in a southern Italian town. Am J Gastroenterol 2009; 104:27402746.

12. Tanaka J, Kumagai J, Katayama K, Komiya Y, Mizui M, Yamanaka R, et al. Sex- and age-specific carriers of hepatitis B and $\mathrm{C}$ viruses in Japan estimated by the prevalence in the 3,485,648 first-time blood donors during 1995-2000. Intervirology 2004; 47:32-40.

13. Meffre C, Le Strat Y, Delarocque-Astagneau E, Dubois F, Antona D, Lemasson JM, et al. Prevalence of hepatitis B and hepatitis C virus infections in France in 2004: social factors are important predictors after adjusting for known risk factors. J Med Virol 2010; 82:546-555.

14. Huang CF, Chuang WL, Yu ML. Chronic hepatitis C infection in the elderly. Kaohsiung J Med Sci 2011; 27:533-537.

15. Pereira LM, Martelli CM, Moreira RC, Merchan-Hamman E, Stein AT, Cardoso MR, et al. Prevalence and risk factors of Hepatitis C virus infection in Brazil, 2005 through 2009: a cross-sectional study. BMC Infect Dis 2013; 13:60.

16. Fagundes GD, Bonazza V, Ceretta LB, Back AJ, Bettiol J. Detection of the Hepatitis $\mathrm{C}$ virus in a population of adults. Rev Lat Am Enfermagem 2008; 16:396-400.

17. Naing L, Winn T, Rusli BN. Practical Issues in Calculating the Sample Size for Prevalence Studies. Arch Orofac Sci 2006; 1:9-14.
18. Mayfield D, McLeod G, Hall P. The CAGE questionnaire: validation of a new alcoholism screening instrument. Am J Psychiatry 1974; 131:1121-1123.

19. Current cigarette smoking prevalence among working adults--United States, 2004-2010. MMWR Morb Mortal Wkly Rep 2011; 60:1305-1309.

20. Sociedade Brasileira de Hepatologia (SBH). Relatório do Grupo de Estudo da Sociedade Brasileira de Hepatologia. Epidemiologia da Infecção pelo Vírus da Hepatite C no Brasil. SBH: GED; 1999. p. 53-58.

21. Rosini N, Mousse D, Spada C, Treitinger A. Seroprevalence of HbsAg, Anti-HBc and anti-HCV in Southern Brazil, 1999-2001. Braz J Infect Dis 2003; 7:262-267.

22. Focaccia R, Conceicao OJ, Sette Jr H, Sabino E, Bassit L, Nitrini DR, et al. Estimated Prevalence of Viral Hepatitis in the General Population of the Municipality of São Paulo, Measured by a Serologic Survey of a Stratified, Randomized and Residence-Based Population. Braz J Infect Dis 1998; 2:269-284.

23. Wasley A, Alter MJ. Epidemiology of hepatitis C: geographic differences and temporal trends. Semin Liver Dis 2000; 20:1-16.

24. Silveira L, Schiavon LL, Silva KP, Lopes TB, Zaccaron Mda R, NarcisoSchiavon JL. Clinical and epidemiological profile of blood donors with positive serology for viral hepatitis in southern Brazil. Rev Soc Bras Med Trop 2011; 44:269-273.

25. Saltoglu N, Tasova Y, Burgut R, Dundar IH. Sexual and non-sexual intrafamilial spread of hepatitis $\mathrm{C}$ virus: intrafamilial transmission of HCV. Eur J Epidemiol 1998; 14:225-228.

26. Donahue JG, Munoz A, Ness PM, Brown Jr DE, Yawn DH, McAllister $\mathrm{Jr} \mathrm{HA}$, et al. The declining risk of post-transfusion hepatitis $\mathrm{C}$ virus infection. N Engl J Med 1992; 327:369-373.

27. Zou S, Stramer SL, Dodd RY. Donor testing and risk: current prevalence, incidence, and residual risk of transfusion-transmissible agents in US allogeneic donations. Transfus Med Rev 2012; 26:119-128.

28. Kupek E. Transfusion risk for hepatitis B, hepatitis C and HIV in the state of Santa Catarina, Brazil, 1991-2001. Braz J Infect Dis 2004; 8:236-240.

29. Hauri AM, Armstrong GL, Hutin YJ. The global burden of disease attributable to contaminated injections given in health care settings. Int $\mathrm{J}$ STD AIDS 2004; 15:7-16.

30. Nelson PK, Mathers BM, Cowie B, Hagan H, Des Jarlais D, Horyniak D, Degenhardt L. Global epidemiology of hepatitis B and hepatitis C in people who inject drugs: results of systematic reviews. Lancet 2011; 13:571-583.

31. Ernst E, Sherman KJ. Is acupuncture a risk factor for hepatitis? Systematic review of epidemiological studies. J Gastroenterol Hepatol 2003; 18:1231-1236.

32. Levin KA. Study design IV. Cohort studies. Evid Based Dent 2006; 7:51-52.

33. Levin KA. Study design III: Cross-sectional studies. Evid Based Dent 2006; 7:24-25. 